\title{
Evaluation of road safety installations with a model rutting tester
}

\author{
K. Sokolov ${ }^{1}$, M. Stimolo ${ }^{1}$, H. M. Burger ${ }^{2}$ and M. N. Partl ${ }^{1}$ \\ (1) Empa, Swiss Federal Laboratories for Materials Testing and Research, Laboratories for Road Engineering / Sealing \\ Components, Überlandstrasse 129, CH-8600 Dübendorf, Switzerland \\ (2) Technical Advice \& Consulting AG, 8704 Herrliberg, Switzerland
}

Received: 23 November 2004; accepted: 27 January 2005

\begin{abstract}
Passively lighted reflector systems are used increasingly for improving pedestrian security. They are glued on the road surface in front of pedestrian crossings and are exposed to any kind of traffic loading. In order to achieve durable and reliable functioning of these reflectors, the mechanical behaviour of the road reflectors themselves, as well as the contact zone between the reflectors and the road surface under alternating wheel loading plays a critical role. The reflector system consisted of the reflector with special glue and a cover material. A one third scale model mobile load simulator (MMLS3) was used to investigate the traffic load performance of the reflector-road construction for both old and new compacted asphalt pavement specimens at two different elevated constant temperatures. It was observed that the contact zone between the reflector and surface of the new specimen was destroyed in the rutting zone after some thousands of cycles. In order to determine the position and shape of cavities and debonding effects in one tested specimen, infrared (IR) thermography measurements were carried out. In addition to the MMLS3 traffic simulation tests, resistance to temperature cycles was tested on an old compacted asphalt pavement specimen with the aim to investigate the adhesive behaviour of the reflectors and cover material after 20 temperature cycles. Quasistatic pull-off tests were carried out on all reflectors except for the reflectors on the new asphalt specimen.

1359-5997@ 2005 RILEM. All rights reserved.

\section{RÉSUMÉ}

Les réflecteurs lumineza sont de plus en plus utilisés sur les chaussées pour augmenter la sécurité des piétons. Ces réflecteurs sont collés à la surface de la chaussée sur les côtés des passages pour piétons et ils sont ainsi exposés aux charges du trafic. Afin d'assurer un fonctionnement fiable et durable de ces réflecteurs, le comportement mécanique des réflecteurs eux-mêmes ainsi que la zone de contact entre le réflecteur et la chaussée sous les charges alternées des roues jouent un rôle critique. Ce système de réflecteur est formé du réflecteur proprement dit, d'un adhésif spécial et d'une couche de protection. Un simulateur de charges mobiles à l'échelle 1/3 (MMLS3) a été utilisé pour étudier le comportement de l'ensemble réflecteurchaussée sous les charges du trafic avec des éprouvettes en enrobé fraîchement compacté et des éprouvettes en enrobé compactées de longue date, cela à deux températures constantes. Les observations ont montré que sur les éprouvettes fraichement compactées, la zone de contact entre le réflecteur et la surface était détruite après quelques milliers de cycles dans la zone de roulement. Des mesures par thermographie infrarouge ont été effectuées afin de déterminer la position et la forme des cavités ainsi que des décollements. En plus des essais de simulation du trafic sur le MMLS3, on a également réalisé des essais de résistance à des cycles de température sur une éprouvette d'enrobé compactée de longue date pour étudier le comportement de l'adhésif et du matériau du revêtement de protection après 20 cycles de température. Des essais de traction quasi-statiques ont encore été effectués sur tous les réflecteurs en place sur les éprouvettes, à l'exception de ceux posés sur les éprouvettes fraîchement compactées.
\end{abstract}

\section{INTRODUCTION}

The objectives of the research study were as follows:

- Investigate and assess the mechanical behavior of the glued HMB-reflectors, the 2-component HMB-glue and the 2-component HMB-cover material at different hot weather temperatures with a third scale model mobile load simulator MMLS3 (produced by MLS Test Systems cc) on a new and an old asphalt concrete pavement.

- Investigate the resistance to temperature cycles of the HMB-reflector which was glued onto the road surface.

- Carry out quasistatic pull-off tests on all reflectors and

\section{Editorial note}

EMPA is a RILEM Titular Member. Dr. Manfred N. Partl is a RILEM Senior Member. He is the Chairman of RILEM TC ATB 'Advanced testing and characterization of bituminous materials' and participates in RILEM TCs 197-NCM 'Nanotechnology in construction materials' and CAP 'Cracking in Asphalt Pavements'. 
evaluate their results with respect to the durability of the combined reflector-road construction.

- Evaluate the suitability of MMLS3 for reflector testing and the possibilities of non-destructive IR thermography damage detection in this special case.

The following tests were performed to achieve the objectives:

- For traffic load performance testing with MMLS3, two compacted asphalt pavement slabs were used: Series A (old pavement) and Series B (newly compacted pavement). In Series A the HMB-reflectors were tested in a climate chamber at two elevated constant temperatures $\mathrm{T}=30^{\circ} \mathrm{C}$ (experiment $\mathrm{A} 30$ ) and $\mathrm{T}=40^{\circ} \mathrm{C}$ (experiment A40). In Series $B$ tests were conducted at one temperature $\mathrm{T}=40^{\circ} \mathrm{C}$ (experiment B40). The temperature was measured at the surface of each specimen and was constant over the whole specimen thickness. Both Series A and B were tested under ambient relative humidity conditions. Two HMB-reflectors were applied for every experiment. One reflector was arranged perpendicular to the longitudinal axis of MMLS3 whereas the other one was located in an angle of $45^{\circ}$ to this axis. The vertical displacements of the specimen surface were measured and recorded periodically during the tests.

- In order to investigate resistance to temperature cycles, one HMB-reflector was glued on the surface of an old asphalt pavement specimen (the same material as in the Series A) and subjected to 20 temperature cycles with testing temperatures periodically varying between $-15^{\circ} \mathrm{C}$ and $+40^{\circ} \mathrm{C}$.

- Pull-off tests were carried out on all HMB-reflectors of the Series $A$ at the end of the MMLS3 traffic load simulation and the cyclic temperature test. The pull-off tests were performed up to fracture, and the maximum tensile force was measured and recorded.

- Infrared (IR) thermography was used with the aim of determining the position and shape of cavities and debonding defects which occurred in the MMLS3 test (Series B) under the HMB-reflectors and HMB-cover material.

\section{MATERIALS}

\subsection{2-component HMB-glue and 2-component HMB-cover material}

The 2-component HMB-glue (ZR 070202/3) and the 2component HMB-cover material (ZR 271000/29) are specially designed for the application of the HMB-reflectors according to the formulas of the company Coverplast. These products consist of binder, fillers and additional materials. The binders of these products are monomeric systems with methacrylic acid methylester (MMA) as major part and, if necessary, comonomers as admixture.

\subsection{HMB-reflector}

The HMB-reflector (Fig. 1) has dimensions of $450 \times 150 \times 9 \mathrm{~mm}$ and is made of the plastic ABS E200. Its cross-ribs have a length of $75 \mathrm{~mm}$ (horizontal projection) (a)

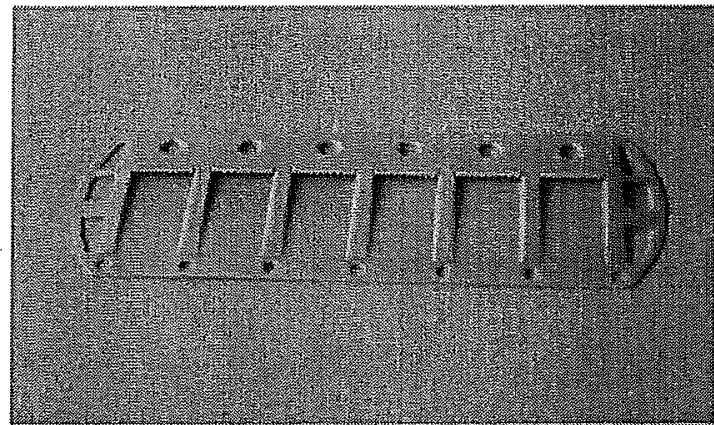

(b)

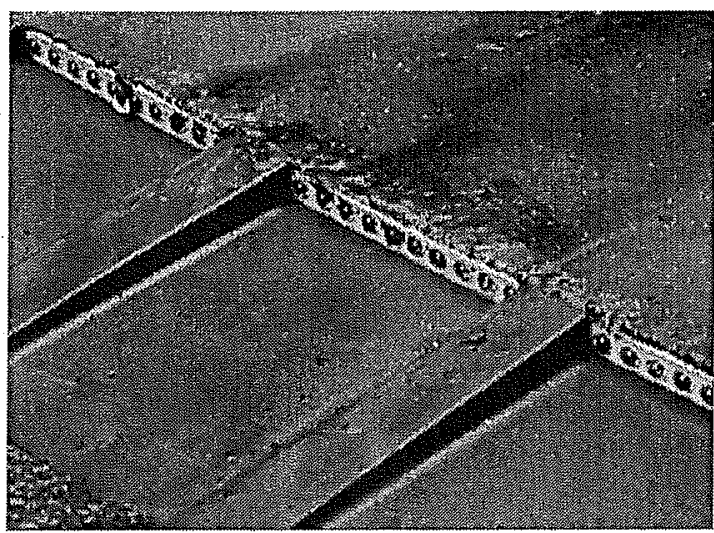

Fig. 1 - HMB-reflector: generally view (a); applied on the road surface (b).

and $a$ width of $14 \mathrm{~mm}$. The overall internal distance between the ribs is $47 \mathrm{~mm}$.

\section{EXPERIMENTS}

\subsection{Testing of traffic load performance with MMLS3}

\subsubsection{Principle of MMLS3}

The purpose of MMLS3 is the accelerated laboratory and field testing of the mechanical behavior of pavements under one-way moving dynamic traffic loads, especially the investigation of the surface courses with regard to the permanent deformation (rutting). In this case MMLS3 was also used for testing the resistance to dynamic traffic loads during the wheel passing over the reflectors, in particular the resistance to the corresponding horizontal shear loads. These dynamic traffic loads are generally assumed to produce stressstrain situations within the linear viscoelastic range [1].

The functioning of MMLS3 has been reported in detail elsewhere [3-5]. Fig. 2 shows the principle of the MMLS3. Table 1 reports the parameters which were chosen in these reflector tests.

\subsubsection{Preparation of the tests}

For the MMLS3 testing two compacted asphalt pavement slabs were used:

- An old three layer slab with an asphalt concrete surface course AB11 from EMPA stock (Series A). This slab 
was taken more than 20 years ago from a highway with a fairly heavy traffic after many years of use. Its dimensions were $1900 \times 750 \times 280 \mathrm{~mm}$.

- A new two layer slab with a surface course AB11 (Series B) which was paved about 2 month before testing and taken the next day. It had dimensions of $1500 \times 800 \times 160 \mathrm{~mm}$.

Both slabs were installed in open air in a reinforced concrete frame, see Fig. 3(a). In order to allow curing of the cement mortar, the specimens were left in the open air for 14 days. The mean air temperature during daytime was about $25^{\circ} \mathrm{C}$.

After curing of the cement mortar, the HMB-reflectors were applied in two steps. In a first step the reflector was glued on the pavement surface. In a second step the 2component HMB-cover material was applied to the border zones of the HMB-reflectors and to the adjacent zones of the pavement surface. The application of the 2-component HMB-cover material was performed in 4 steps.

Overall, 6 reflectors were applied, 2 reflectors for each of the tests $\mathrm{A} 30$ (constant testing temperature $\mathrm{T}=30^{\circ} \mathrm{C}$ ), $\mathrm{A} 40$ and $\mathrm{B} 40$ (testing temperature $\mathrm{T}=40^{\circ} \mathrm{C}$ ). One of the reflectors was arranged perpendicular to the longitudinal axis of MMLS3 (labeled with $N$ in Fig. 3), another one was located in an angle of $45^{\circ}$ to this axis (labeled with $\mathrm{S}$ in Fig. 3). The reflecting elements of the perpendicular reflectors showed towards the driving direction (corresponding to the "normal" traffic situation) and their fixation in the socket of the reflector was therefore tested in a compression mode. The reflecting elements of the $45^{\circ}$ oriented reflectors showed away from the driving direction (Fig. 3) which had the effect that the fixation of the reflector elements in the socket of the reflector was tested in a tension mode. The MMLS3 was placed on the testing specimen as shown in Fig. 4. To achieve constant testing temperature a closed aluminum container was built around the whole testing configuration. Hence, the testing temperature during testing varied by $\max . \pm 1^{\circ} \mathrm{C}$.

\subsubsection{Measurement}

A special profilometer (produced by MLS Test Systems cc) was used in order to measure the rut depths. It was installed under the MMLS3 perpendicular to the driving direction (Fig. 5). For reproducibility reasons the profilometer was mounted on "reference points". The measurement and recording of testing data was done automatically.

After placing the MMLS3 on the specimen, a zero measurement was performed for the unloaded condition as reference for the following measurements. The development of rutting in the tests A30, A40, and B40 was measured and recorded with the profilometer periodically up to 2 million wheel passings. It was measured in transverse profiles which were located $50 \mathrm{~mm}$ apart from each other. The absolute measuring accuracy was $\pm 0.1 \mathrm{~mm}$. As shown in Fig. 6 (Series A), the transverse measurements for all tests started at the origin of the chosen coordinate system. The distance between the transverse measurement points was $5 \mathrm{~mm}$. After determination of each profile, the

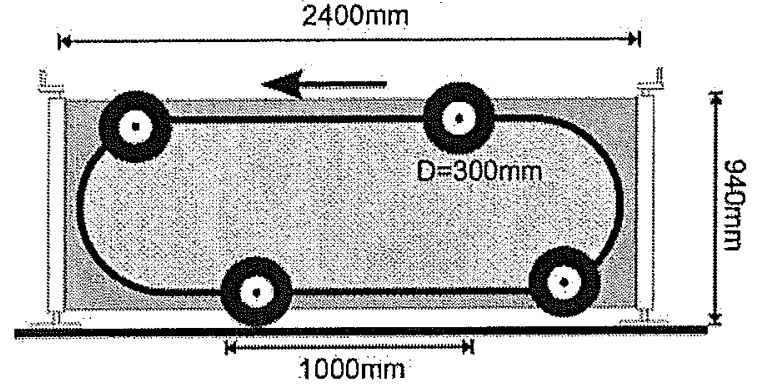

Fig. 2 - Diagram of MMLS3.

\begin{tabular}{|c|c|c|c|c|}
\hline \multicolumn{5}{|c|}{ Table 1-MMLS3: Technical specifications } \\
relevant for the reflector tests \\
\hline $\begin{array}{c}\text { Wheel } \\
\text { diameter } \\
(\mathrm{mm})\end{array}$ & $\begin{array}{c}\text { Tire } \\
\text { width } \\
(\mathrm{mm})\end{array}$ & $\begin{array}{c}\text { Tire } \\
\text { footprint } \\
\text { area } \\
\left(\mathrm{cm}^{2}\right)\end{array}$ & $\begin{array}{c}\text { Tire } \\
\text { contact } \\
\text { pressure } \\
(\mathrm{kPa})\end{array}$ & $\begin{array}{c}\text { Nominal } \\
\text { load per } \\
\text { wheel (N) }\end{array}$ \\
\hline 30 & 80 & 34 & 620 & 2100 \\
\hline
\end{tabular}

(a)

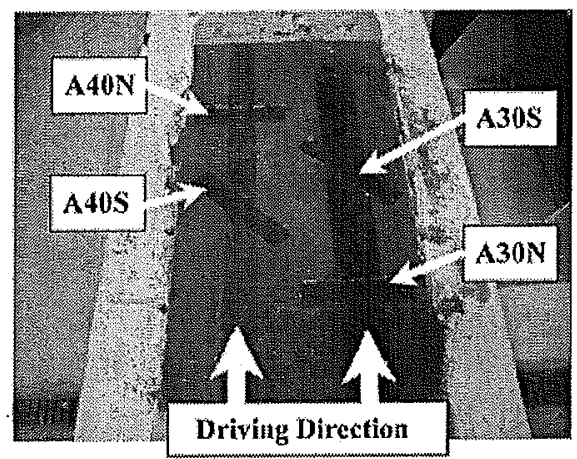

(b)

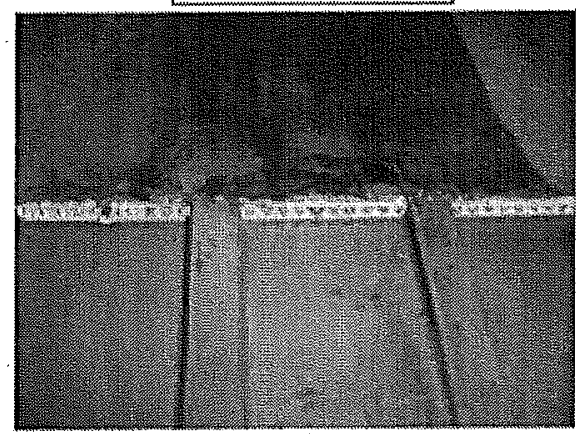

(c)

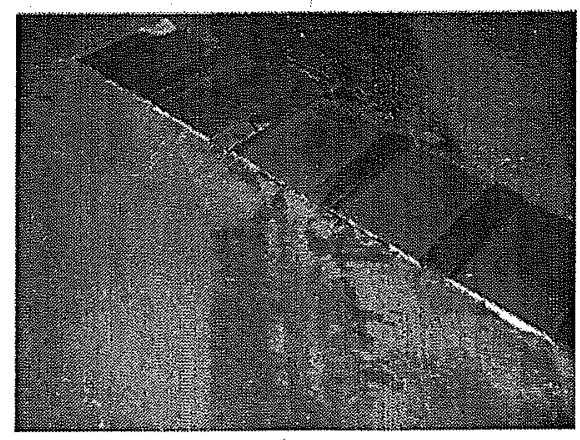

Fig. 3 - Arrangement of the HMB-reflectors (series A): general view of the testing slab and reflectors labels (a); reflector $\mathrm{A} 30 \mathrm{~N}(\mathrm{~b})$; reflector $\mathrm{A} 30 \mathrm{~S}$ (c). 
next profile in the longitudinal direction towards the driving direction was measured. In this way, 12,11 and 11 profiles were recorded for the tests $A 30, A 40$ and $B 40$, respectively.

\subsection{Resistance to temperature cycles}

In order to investigate the resistance to temperature cycles, a specimen from Series A was prepared. Again, a HMB-reflector was glued on its surface with the 2component HMB-glue and covered with the 2-component HMB-cover material. The horizontal dimensions of the specimen were $600 \times 300 \mathrm{~mm}$. The prepared specimen was thermally insulated at the sides with polystyrene panels. After that, the specimen was laid on a wooden plate and placed into a temperature chamber. The temperature was measured with a temperature sensor which was attached to the surface of the applied reflector.

In this test 20 trapezoidal temperature cycles were performed. The testing temperature varied linearly during 90 minutes between $-15^{\circ} \mathrm{C}$ and $+40^{\circ} \mathrm{C}$ followed by a constant temperature phase of another 90 minutes. Hence, one full testing cycle took 6 hours.

\subsection{Pull-off tests}

For the preparation of the pull-off tests the chosen testing location had to be leveled out mechanically. For this reason the middle ribs of the HMB-reflectors were removed with a heated putty-knife. After that the circular cuts were made with a $50 \mathrm{~mm}$ core. Depending on the testing location the circular cut reached the pavement surface. A $50 \mathrm{~mm}$ circular steel plate was glued on the testing location with a 2-component glue. After curing of the glue the steel plate was connected to the servo hydraulic testing machine and vertically pulled with a load controlled velocity of $200 \mathrm{~N} / \mathrm{s}$ (Fig. 7). All pull-off tests were carried out at room temperature of about $\mathrm{T}=23^{\circ} \mathrm{C}$ up to fracture, and the maximum tensile force was measured and recorded.

\subsection{IR-Thermography}

\subsubsection{Inspection principle}

At EMPA, passive thermography is used as a thermal non-destructive testing method in search for hidden defects and/or damages in a road or bridge pavement structure (layered structure), based on the use of a heat flow to investigate their inner structure. The conduction heat flow $\mathrm{q}$ in the $\mathrm{z}$ direction along the object thickness is described by Fourier's law:

$$
q_{\text {Conduction }}=-k * \partial T / \partial z \text {. }
$$

The method exploits the insulation effect by thermal diffusion caused by the defects and discontinuities, i.e. the thermal resistance $\left(R_{W}=L * k^{-1} * A^{-1} ;\left[\mathrm{K} \mathrm{W}^{-1}\right]\right)$ of the defect is higher than the areas with no defects in the sample. Hence, the air trapped in the delaminated defects (typical for example for adhesion problems in a layered structure) acts thermo-physically as an insulation region; disturbing the heat flow in the specimen $\left(\mathrm{k}_{\text {Air; }} \mathrm{T}=20^{\circ} \mathrm{C} ; \mathrm{p}=1\right.$ bar $=$

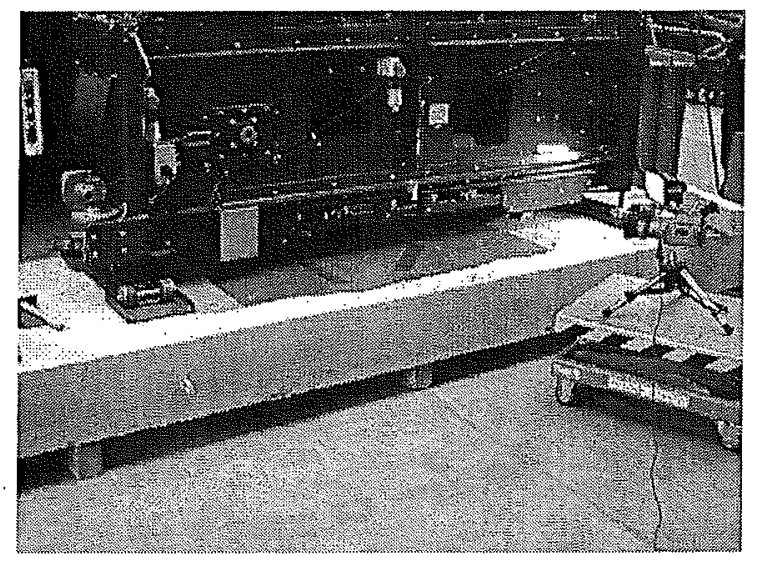

Fig. 4 - MMLS3, placed on the specimen (series A).

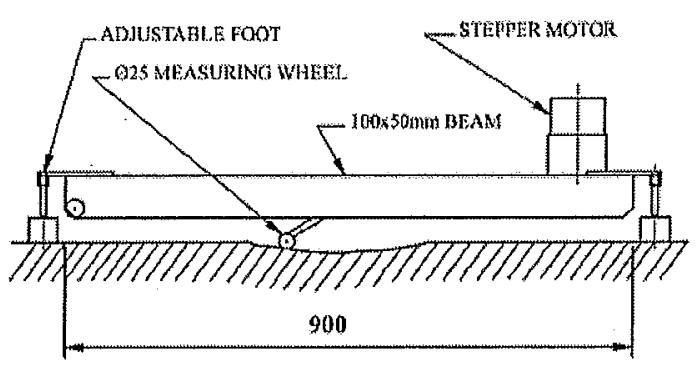

Fig. 5 - MMLS3 profilometer (source: MLS Test Systems cc).

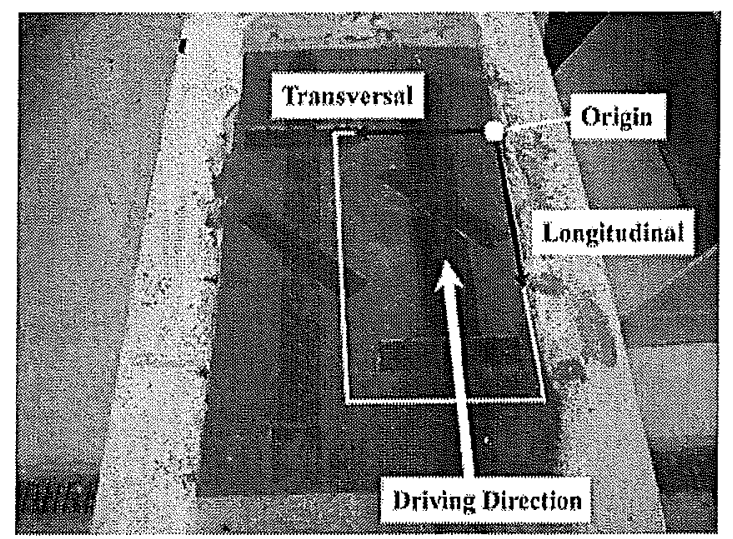

Fig. 6-Measuring area (test A30).

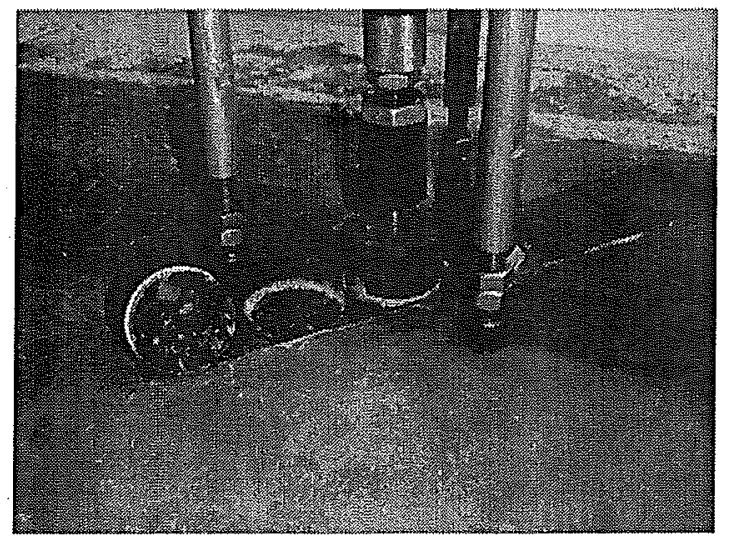

Fig. 7 - Pull-off test equipment, working zone. 
$\left.26.03 \times 10^{-3} \mathrm{Wm}^{-1} \mathrm{~K}^{-1} ; \mathrm{k}_{\text {Pavement }}=0.53 \ldots 1.87 \mathrm{Wm}^{-1} \mathrm{~K}^{-1}\right)$. Therefore, a temperature difference $\left(\Delta T=T_{d}-T_{n d}\right)$ develops at the surface between the hotter region above the defect $T_{d}$ and its non-defect surroundings $T_{\text {nd }}$ that can be detected with the IR-camera. Depending on the observation technique (transmission, reflection), the temperature difference can be positive for the transmission technique, or negative for the reflection technique.

In fact, two methods of observation are possible: in reflection, both the thermal source and the detector unit are located on the same side of the work piece; in transmission, the thermal source and detector unit are located on opposite sides of work piece [2].

IR thermography can also be used to display the location and the planar shape and extension of the defects buried in the specimen. Usually, a sample is in a state of thermal balance with the ambient. Therefore the thermal balance must be altered through a heating or cooling method in order to induce a thermal gradient and to allow an IR investigation. The key to a successful inspection of the delaminated defect is a correct choice of the type, intensity and duration of this thermal alteration as well as of the timing of the recorded signal.

When the sample is heated or cooled rapidly, a strong warm or cool flow can lead to a very abrupt change of the temperature field on the sample surface and to a higher inspection sensitivity. The heating or cooling method must generate a uniform surface temperature field $T(x, y, t)$ on the surface of a sample in order to obtain a uniform heat flow in the sample.

\subsubsection{Preparation and IR measurement}

During the recording of the thermograms the cooling down technique has been used. This teclinique consists of taking the thermograms during the cooling phase of the investigated area. In this case the cooling occurs through the natural convection. In a sample with a layered structure it is favorable that the layers have a constant thickness $(L=$ const) otherwise the surface temperature field does not appear uniform in the thermogram (this is also quite evident from $R_{W}$ ).

In order to apply the cooling down IR measurement method, in this study, the specimen was first heated up with a heat transfer medium placed above the upper surface of the specimen. The heat transfer medium consisted of a plastic sheet and one layer of crushed sand $0 . .3 \mathrm{~mm}$ with a thickness of approximately $80 \mathrm{~mm}$. The crushed sand was heated during a week-end in a furnace at approximately $80^{\circ} \mathrm{C}$. This medium was able to store and transfer the heat to the upper surface of the specimen within approximately 20 minutes. The medium was also able to adapt to the surface unevenness of the specimen in order to guarantee a good thermal contact between the two surfaces. Moreover it was easy and quick to remove.

In order to slow down the cooling due to convection, the remaining exposed parts of the heat transfer medium were cautiously covered with polystyrene panels.

The infrared measurement system for this investigation consisted of an infrared camera (IR-camera) AGEMA THV $900 \mathrm{LW}$ (Long Wave, of 8 to $12 \mu \mathrm{m}$ ) with lens $40^{\circ} \times 20^{\circ}$.
A system of thermocouple and slab of copper was placed in the middle of the upper surface of the sample (see TC in Fig. 8) for monitoring the temperature between the heat transfer medium and the upper surface of the specimen.

\section{RESULTS AND DISCUSSION}

\subsection{MMLS3 test results}

Figs. 9 and 10 show the development of the maximum rut depths in Series A with growing number of wheel passings. The rut depths were recorded in the longitudinal profiles in the middle of the rut at a distance of $50 \mathrm{~mm}$. Negative values denote downward, positive values upward displacement. Table 2 contains the values of the maximum rut depths for all performed MMLS3 tests.

It can be clearly seen that for both tests of Series A after approx. 0.5 millions wheel passings there is practically no increase in rut depth. In addition, the development of rutting at $40^{\circ} \mathrm{C}$ is considerably faster than at $30^{\circ} \mathrm{C}$, producing results which are apparently less influenced by local disturbances like in case of the abnormal increase of deformation under the diagonally applied reflector A30S. This was one of the reasons why Series B was only tested at $40^{\circ} \mathrm{C}$. For Series A the visual observation of the tested HMB-reflectors and the 2-component HMB-cover material in the ruts and in the border areas showed no local damages. Furthermore no loss of adhesion between the HMB-glue layer and pavements surface was observed.

Fig. 11 shows the development of the maximum rut depths for Series $B$ at $40^{\circ} \mathrm{C}$. Rut depths measured in this series after
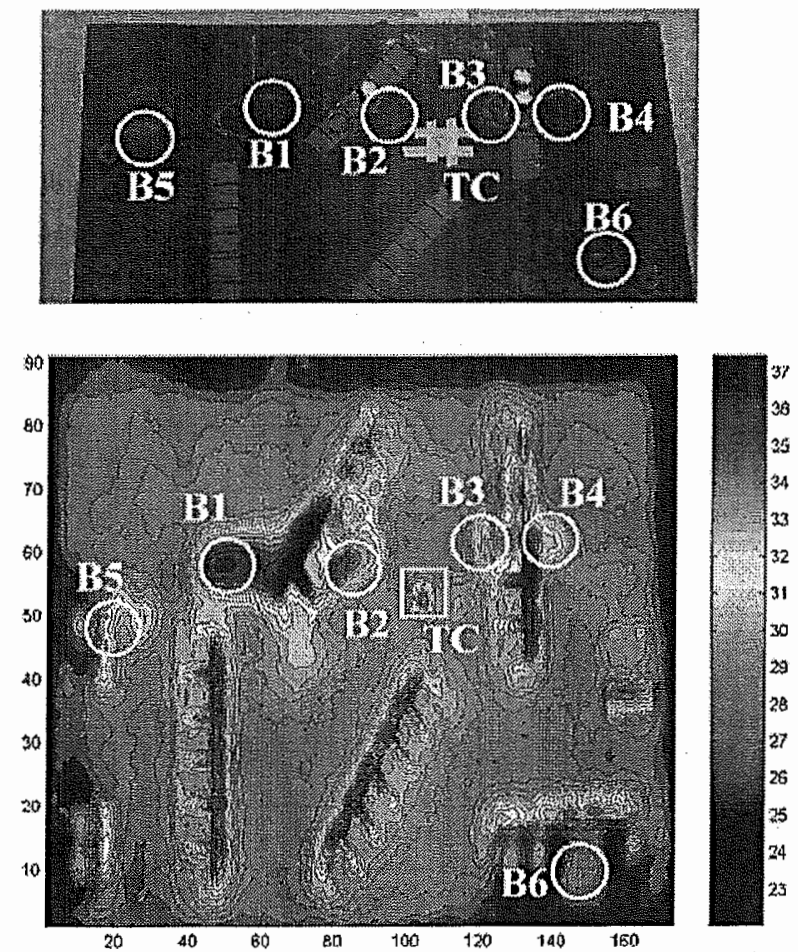

Fig. 8 - Visual and thermal images of the specimen (cover and HMB-reflectors). 


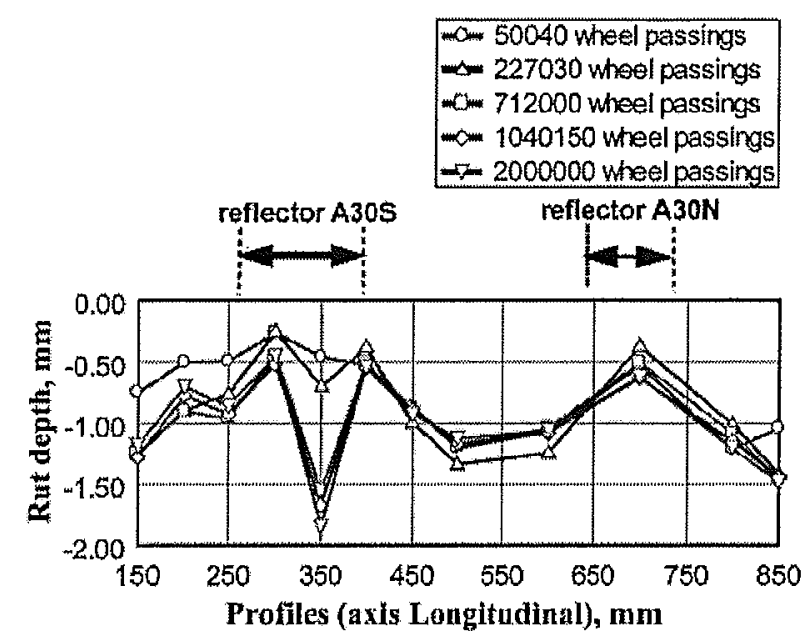

Fig. 9 - Rut depths, experiment A30: longitudinal profile in the middle of the rut.

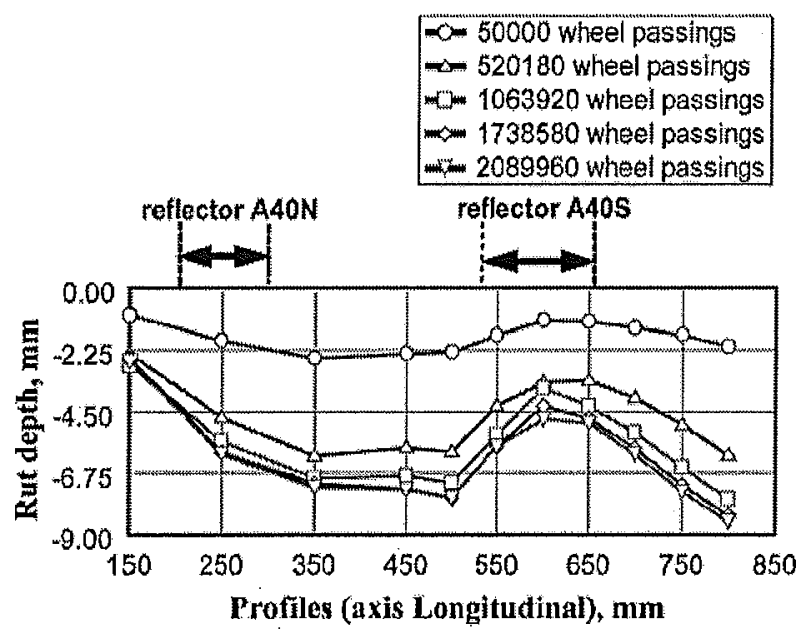

Fig. 10 - Rut depths, experiment A40: longitudinal profile in the middle of the rut.

$50^{\prime} 000$ wheel passings show similar values as in test $\mathrm{A} 40$ (Fig. 10). However, the rut depth after approx. 500'000 wheel passings is considerably smaller. After 1'000'500 wheel passings the measured values of the rut depths are even smaller then after $50^{\prime} 000$ passings at the beginning of the test. The reason for this is the elastic recovery of the surface after debonding of the HMB-reflectors and HMB-cover material from the pavement surface (Fig. 12).

\subsection{Pull-off test results}

Results of the pull-off tests at room temperature are summarized in Table 3. In this table the tests TI to T3 were performed on the reflector on the specimen of the resistance to temperature cycles test; the tests $\mathrm{A} 30 \mathrm{Sx}, \mathrm{A} 30 \mathrm{Nx}, \mathrm{A} 40 \mathrm{Sx}$, A40Nx correspond to the reflectors of the MMLS3-Series A. It is obvious that the failure stresses for the old pavement specimen is practically independent of the application direction of the reflector and the MMLS3 testing temperature. On the other hand, a clear influence of

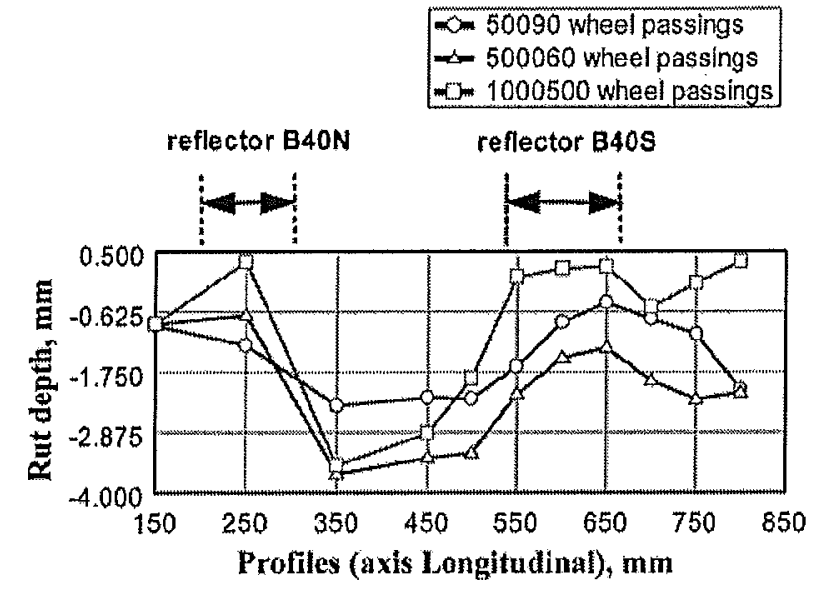

Fig. 11 - Rut depths, experiment B40: longitudinal profile in the middle of the rut.

\begin{tabular}{|c|c|c|}
\hline \multicolumn{2}{|c|}{ Table 2 - MMLS3 tests, measured rut depths } \\
\hline Test & Wheel passings & $\begin{array}{c}\text { Maximum rut depth } \\
\text { (mm) }\end{array}$ \\
\hline \multirow{4}{*}{ A30 $\left(\mathrm{t}=30^{\circ} \mathrm{C}\right)$} & 50040 & -1.347 \\
\cline { 2 - 3 } & 227030 & -2.025 \\
\cline { 2 - 3 } & 712000 & -2.779 \\
\cline { 2 - 3 } & 1040150 & -3.252 \\
\cline { 2 - 3 } & 2000000 & -3.765 \\
\hline \multirow{4}{*}{$\mathrm{A} 40\left(\mathrm{t}=40^{\circ} \mathrm{C}\right)$} & 50000 & -2.678 \\
\cline { 2 - 3 } & 520180 & -6.249 \\
\cline { 2 - 3 } & 1063920 & -8.039 \\
\cline { 2 - 3 } & 1738580 & -8.740 \\
\cline { 2 - 3 } & 2089960 & -8.996 \\
\hline \multirow{3}{*}{$\mathrm{B} 40\left(\mathrm{t}=40^{\circ} \mathrm{C}\right)$} & 50090 & -2.377 \\
\cline { 2 - 3 } & 500060 & -3.660 \\
\cline { 2 - 3 } & 1000500 & -3.496 \\
\hline
\end{tabular}

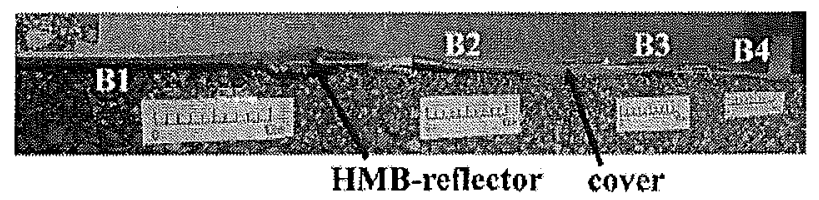

Fig. 12 - Vertical section of the longitudinal cut (B1U, B2U, B3U, B4U).

temperature cycles on the pull-off strength appears to exist. As compared to the MMLS3 specimens, the reduction of the pull-off failure stress is more then $20 \%$.

The failure zone in all pull-off tests was located in the asphalt surface course and not in the HMB-glue layer.

\subsection{IR test results}

The aim of this thermal non-destructive evaluation was the detection of possible defects and discontinuities through a qualitative comparison of the surface temperature signals 


\begin{tabular}{|c|c|c|c|c|}
\hline \multicolumn{5}{|c|}{ Table 3 - Results of the pull-off tests $\left(\mathbf{2 3}{ }^{\circ} \mathbf{C}\right)$} \\
\hline Test & $\begin{array}{c}\text { Steel } \\
\text { plate } \\
\text { diameter } \\
(\mathbf{m m})\end{array}$ & $\begin{array}{c}\text { Maximum } \\
\text { load (kN) }\end{array}$ & $\begin{array}{c}\text { Pull-off } \\
\text { failure } \\
\text { stress } \\
\text { (MPa) }\end{array}$ & $\begin{array}{c}\text { Mean value of the } \\
\text { pull-off failure } \\
\text { stress } \\
\text { (MPa) }\end{array}$ \\
\hline T1 & 49.2 & 2.98 & 1.567 & \multirow{2}{*}{1.620} \\
\hline T2 & 48.3 & 3 & 1.637 & \\
\hline T3 & 49.3 & 3.16 & 1.655 & \\
\hline A30S1 & 49.2 & 4.38 & 2.304 & \multirow{2}{*}{2.071} \\
\hline A30S2 & 49.3 & 3.78 & 1.980 & \\
\hline A30S3 & 49.4 & 3.7 & 1.930 & \multirow{2}{*}{2.061} \\
\hline A30N1 & 49.5 & 4.04 & 2.099 & \\
\hline A30N2 & 49.5 & 3.9 & 2.027 & \multirow{2}{*}{2.020} \\
\hline A30N3 & 49.4 & 3.94 & 2.056 & \\
\hline A40N1 & 49.2 & 4.14 & 2.178 & \multirow{2}{*}{1.924} \\
\hline A40N2 & 49.2 & 3.42 & 1.799 & \\
\hline A40N3 & 49.3 & 3.98 & 2.085 & \\
\hline A40S1 & 49.3 & 3.42 & 1.792 & \\
\hline A40S2 & 49.2 & 3.92 & 2.062 & \\
\hline A40S3 & 49.3 & 3.66 & 1.917 & \\
\hline
\end{tabular}

\begin{tabular}{|c|c|c|c|c|c|}
\hline \multicolumn{6}{|c|}{ Table 4-Summary of six regions of interest (ROIs) } \\
\hline \multicolumn{6}{|c|}{ Longitudinal cut } \\
\hline Denomination & $\begin{array}{c}\text { Length } \\
\text { (cm) }\end{array}$ & $\begin{array}{c}\text { Height } \\
(\mathrm{cm})\end{array}$ & $\begin{array}{l}\text { Depth } \\
\text { (cm) }\end{array}$ & $\begin{array}{c}\bar{T} \\
\left({ }^{\circ} \mathrm{C}\right)\end{array}$ & Comment \\
\hline BIU & 41.0 & 0.60 & 0.50 & 35.9 & \\
\hline $\mathrm{B} 1 \mathrm{D}$ & 35.0 & 0.60 & 0.50 & & $\begin{array}{l}\text { Depth below } \\
\text { HMB-reflector } \\
=2.0 \mathrm{~cm}\end{array}$ \\
\hline $\mathrm{B} 2 \mathrm{U}$ & 19.0 & 0.70 & 0.90 & 34.4 & $\begin{array}{c}\text { Depth not } \\
\text { constant }\end{array}$ \\
\hline $\mathrm{B} 2 \mathrm{D}$ & 13.0 & 0.80 & 0.50 & & $\begin{array}{l}\text { Depth below } \\
\text { HMB-reflector } \\
=0.80 \mathrm{~cm}\end{array}$ \\
\hline $\mathrm{B} 3 \mathrm{U}$ & 11.8 & 0.25 & 0.50 & 32.5 & \\
\hline $\mathrm{B} 3 \mathrm{O}$ & 9.0 & 0.60 & 0.50 & & $\begin{array}{l}\text { Depth below } \\
\text { HMB-reflector } \\
=0.70 \mathrm{~cm}\end{array}$ \\
\hline $\mathrm{B} 4 \mathrm{O}$ & 9.6 & 0.30 & 0.50 & 32.0 & \\
\hline $\mathrm{B} 4 \mathrm{U}$ & 8.3 & 0.30 & 0.50 & & \\
\hline \multicolumn{6}{|c|}{ Core } \\
\hline Denomination & & $\begin{array}{l}\bar{T} \\
\left.{ }^{\circ} \mathrm{C}\right)\end{array}$ & \multicolumn{3}{|c|}{ Comment } \\
\hline B5 & \multicolumn{2}{|c|}{30.7} & \multicolumn{3}{|c|}{ Cover thickness 4 to $10 \mathrm{~mm}$} \\
\hline B6 & \multicolumn{2}{|c|}{27.8} & \multicolumn{3}{|c|}{ Cover thickness 4 to $7 \mathrm{~mm}$} \\
\hline
\end{tabular}

caused by them. This required a comparison of the local signals of the possible defects with those of areas with no defect.

Fig. 8 shows the thermogram and the visual image of the specimen. The investigated surface has dimensions of $800 \times 1500 \mathrm{~mm}$. The thermogram was taken shortly after removal of the heat transfer medium from the heated specimen surface. For better visualization, the values of the surface temperature were visualized and analyzed with a Matlab application.

From the thermal image it is found that the surface temperature of the zones with no defect ranges between $27.0^{\circ} \mathrm{C}$ and $27.7^{\circ} \mathrm{C}$. The HMB-reflectors are easily recognized by their shape (see Figs. 1 and 8). In addition, six regions of interest (ROI) $\mathrm{B} 1$ to $\mathrm{B} 6$ appear which were supposed to be delamination zones. This was verified by a longitudinal cut between approximately 250 and $280 \mathrm{~mm}$ from the upper edge of the investigated specimen. 'The longitudinal cut crosses the ROIs B1 to B4 and cores of the ROIs B5 and B6 were also taken.

Table 4 reports the parameters of the average surface temperatures $(\bar{T})$ and the geometrical factors measured along the section.

It is concluded that $\mathrm{B} 1$ to $\mathrm{B} 4$ are delaminations (see Fig. 12), while B5 and B6 are caused by the thickness discontinuity of the cover and of the HMB-reflector shape.

Overall it can be concluded that information about location, planar shape and extension of the defect area could be successfully obtained directly from the infrared image. However, false signals (B5, B6) appeared due to the non-uniform thickness.

\section{CONCLUSIONS}

This study led to following main conclusions and findings:

- The model mobile load simulator (MMLS3) can be applied successfully for the optimization and evaluation of reflector systems as described in this study with respect to selected performance related mechanical properties, such as adhesion of the reflector system to the asphalt pavement surface, rutting behavior and mechanical resistance of reflectors to traffic loads.

- For the reflector system investigated herein, it was found, that adhesion is significantly dependent on the surface properties of the pavement. Whereas the reflector system on an old asphalt pavement with a comparatively high amount of uncoated aggregate on its surfaces showed very promising results, the reflector system on a new asphalt pavement with a comparatively high amount of coated aggregate on its surface suffered debonding failures.

- Rutting in the MMLS3 tests at $40^{\circ} \mathrm{C}$ was considerably faster then at $30^{\circ} \mathrm{C}$ and was apparently less influenced by local disturbances.

- The orientation of the reflectors with respect to the driving direction had no significant influence on rutting.

- Pull-off failure stresses at room temperature after rutting tests were practically independent of the application direction of the reflector and the MMLS3 testing temperature.

- As far as the resistance to temperature cycles is concerned, a clear influence on the pull-off strength appears to exist. As compared to the MMLS3 specimens, the reduction of the pull-off failure stress was more than $20 \%$. 
- Using the cooling down method, IR-thermography proved successful in providing useful information about location, planar shape and extension of the debonding defects on a new pavement during MMLS3 rutting.

\section{REFERENCES}

[1] Airey, G.D., Rahimzadeh, B. and Collop, A.C., 'Viscoelastic linearity limits for bituminous materials', Mater. Struct. 36 (December 2003) 643-647.

[2] Maldague, X.P.V., 'Theory and Practice of Infrared Technology for Nondestructive Testing' (Wiley series in microwave and optical engineering, 2001) 351.
[3] Martin Epps, A., Ahmed, T., Little, D.C., Hugo, F., Poolman, P. and Mikhail, M., 'Performance prediction with the MMLS3 at WesTrack', CD-Rom of Proceedings of the Ninth International Conference on Asphalt Pavements, Copenhagen, 17-22 August 2002.

[4] Partl, M.N., Hean, S. and Poulikakos, L., 'Asphaltic Plug Joint Characterization and Performance Evaluation', CD-Rom of Proceedings of the Ninth International Conference on Asphalt Pavements, Copenhagen, 17-22 August 2002.

[5] Smith, A., de Fortier, Hugo, F., Rand, D. and Powell, B., 'Model mobile load simulator testing at national centre for asphalt technology test track', Journal of Transportation Research Record (Washington, D.C., USA) 1832 (2003). 